\title{
Un ambiente enfermo: significados de la contaminación industrial en Isla de Maré, Bahía, Brasil
}

\author{
Maria do Carmo Soares de Freitas, \\ Maria Cecília de Souza Minayo, Paulo Gilvane Lopes Pena \\ y Neuza Maria Miranda dos Santos
}

Para comprender los significados atribuidos a la contaminación industrial por los habitantes de la isla, se optó por un abordaje etnográfico. Se analizó el impacto ambiental a partir de la concepción de la contaminación química de los habitantes locales porque es a lo que más temen. Sus declaraciones revelan posibles categorías analíticas asociadas a sentidos míticos. La contaminación química se caracteriza como una enfermedad del medio ambiente que tiene forma, colores y olores que vienen de fuera y se riegan en los manglares, en el mar y en los poblados. Los modelos explicativos de causalidad y de una semiótica fundada en el saber popular se hacen presentes en las expresiones de los moradores. Este fenómeno afecta la situación socioeconómica y cultural de la población, altera sus condiciones de trabajo, sus hábitos alimenticios y su salud.

PALABRAS CLAVE: significados de la contaminación industrial, antropología ambiental, contaminación, enfermedades, pescadores tradicionales

\section{An III Environment: Meanings Attributed to Industrial Contamination in Ilha de Maré, Bahia, Brazil}

In order to comprehend the meanings attributed to industrial pollution by local inhabitants, an ethnographic approach has been used in this study. We analyze the environmental impact on the basis of local inhabitants' perception of chemical contamination, feared by the population. Their statements reveal possible analytical categories associated to mythical connotations. Chemical contamination is characterized as an environmental disease, whose menace has shape, colors and smells coming from outside and spreading through the mangroves, the towns and the ocean. Explanatory models of causality and of semantics grounded on popular wisdom are manifest in the expressions of the inhabitants. The implications of such a phenomenon impinge upon the population's cultural and socioeconomic situation, modifying their working conditions, their eating habits, and their health.

KEYWORDS: meanings of industrial contamination, environmental anthropology, contamination, disease, traditional fishermen

Maria do Carmo Soares de Freitas: Departamento de Ciencia de la Nutrición, Escuela de Nutrición, Universidad Federal de Bahía, Salvador, Bahía, Brasil carmofreitas@uol.com.br

Maria Cecília de Souza Minayo: Centro Latinoamericano de Estudios de Violencia y Salud “Jorge Careli”, Río de Janeiro, Brasil cecilia@nullclaves.fiocruz.br
Paulo Gilvane Lopes Pena: Facultad de Medicina, Universidad Federal de Bahía, Salvador, Bahía, Brasil plpena@ufba.br

Neuza Maria Miranda dos Santos: Departamento de Ciencia de los Alimentos, Escuela de Nutrición, Universidad Federal de Bahía, Salvador, Bahía, Brasil neuzami@ufba.br 


\section{INTRODUCCIÓN}

$\mathrm{E}$ presente artículo trata de la contaminación ambiental en Isla de Maré - localizada en la Bahía de Todos los Santos (BTs), Salvador, Bahía, Brasil- proveniente de contaminantes químicos arrojados por las industrias químicas, petroquímicas y petrolíferas instaladas en esa región. El propósito es presentar la situación como es percibida por los habitantes del lugar. De acuerdo con los informes oficiales sobre recursos ambientales, la contaminación química que afecta la BTs, en particular metales pesados e hidrocarbonatos de petróleo, llega a índices críticos para la salud humana, la flora y la fauna marina (Bahía-CRA, 2001). El Informe sintético del Centro de Recursos Ambientales de Bahía (Bahía et al., 2005) confirmó situaciones de amenaza al medio ambiente en varias localidades debido a la aguda presencia de ocho contaminantes: arsénico, cadmio, plomo, cobre, cromo, hierro, mercurio y zinc. Uno de los efectos de la contaminación es la modifi-

cación de la cadena alimenticia en los humanos (Okada, 1997): se registró el riesgo carcinógeno relacionado con el consumo de pescado con hidrocarbonatos en varios poblados de la región, cuya absorción es más acentuada en los niños (Mahaffey, 1990; Ziegler et al.,1978).

Existen estudios sobre la contaminación industrial en el estado de Bahía, causada principalmente por metales pesados como plomo y cadmio, que muestran casos de trabajadores expuestos en una fábrica de fundición de plomo en el municipio de Santo Amaro da Purificação, cuyas familias y otros moradores de las cercanías también fueron afectados. Ese impacto ambiental repercutió en el estuario del Río Subaé, BTs y sus comunidades (Silvany-Neto y Carvalho, 1996). En 1996, otro estudio confirmó las altas concentraciones de esos metales en sedimentos y moluscos de todo el ecosistema al norte de la bahía (Tavares y Carvalho, 1992). Los datos oficiales más actuales admiten la presencia de contaminación con metales pesados - mercurio, plomo y cadmio, entre los más tóxicos- en Madre de Deus, poblado cercano a Isla de Maré (Bahía et al, 2005). Se verificó la presencia de otros contaminantes químicos, como los hidrocarburos policíclicos aromáticos (HPA) - como benzo[a]pireno-, los cuales repercuten en la región norte y este de la BTs, además de los puertos de Aratú, Caboto y Pati, cercanos a los poblados de Bananeiras y Maracanã, en Isla de Maré.

En toda la extensión de la bahía se encontraron metales pesados en cantidades que infringen la ley. Específicamente, los moluscos llamados popularmente sururú, rala-coco, lambreta; los crustáceos jaiba, cangrejo y aratú; y los peces tainha, raya, coró, sardina, lenguado y carapeba (Bahía et al., 2005) están contaminados con metales tóxicos como mercurio, plomo, arsénico y cadmio. Cabe destacar que ese tipo de contaminación industrial o química es parte del proceso global de la actual crisis ecológica, implícito en el modelo de desarrollo industrial, de carácter insostenible, que predomina en Brasil y en el mundo. Hace 30 años Ignacy Sachs (1974) definió el desarrollo sostenible, o ecodesarrollo, como una propuesta de viabilidad económica subordinada al desarrollo social, a los valores culturales y a la durabilidad espacial. La cuestión ambiental no es, por tanto, solamente económica, sino que está vinculada a otros aspectos de la vida de las poblaciones. En síntesis, podemos decir que los efectos dañinos en Isla de Maré se presentan como un problema local conjugado con la crisis ambiental globalizada.

Además de la contaminación, hay registros de que el destino de las aguas residuales provenientes de los albañales domésticos e industriales que contaminan las aguas superficiales y subterráneas es el lecho de la BTs (Brasil, 2002). Estos efluentes desaguan al aire libre y constituyen peligrosos focos de diseminación de enfermedades. Esta situación muestra, una vez más, la falta de control de contaminantes domésticos e industriales en países de economía dependiente como el Brasil. A pesar de la magnitud del problema ambiental, no se encontraron estudios sobre la percepción de las poblaciones tradicionales afectadas. La pesquisa, de carácter exploratorio, que dio origen a este trabajo se propone 
contribuir al tema con el análisis de los significados que indican el carácter polisémico del impacto de la contaminación ambiental, principalmente de la contaminación química, como es interpretado por los habitantes de la Isla de Maré. Se busca la contribución de las disciplinas de las ciencias sociales, como la antropología ambiental y de la salud, hacia la comprensión del universo subjetivo y cultural de la crisis ecológica que afecta la salud de la población. El tema de la contaminación química de origen industrial que daña a las poblaciones - en particular la causada por metales pesados- es un asunto complejo y los estudios realizados son insuficientes. Este artículo presenta la percepción de los habitantes de una isla devastada por contaminantes industriales y su impacto al medio ambiente.

La elección de la Isla de Maré para la realización de la investigación que dio origen a este artículo ocurrió un Encuentro de Pescadores y Marisqueras, organizado por la Pastoral de Pesca de Bahía en 2005, cuando los moradores de la isla denunciaron los problemas ambientales y de salud de la población en conexión con la contaminación industrial. Se inició un estudio sistemático de la situación a través de visitas de los investigadores a la isla, con el objeto de preparar y llevar a cabo una revisión empírica del problema. En ese trabajo se dio prioridad a un análisis intersubjetivo, caracterizado por la búsqueda y comprensión de la experiencia de los moradores en su vida relacional, sus acciones, palabras y gestos, evaluando su interpretación individual y grupal en relación con el objeto de estudio (Faustino, 2006). De esa forma, la experiencia del morador de Isla de Maré sobre la contaminación ambiental se refiere a sí y a los demás que viven esa realidad. Las expresiones del lenguaje realzan diversas maneras de significar el problema ambiental y su relación con otros aspectos de lo cotidiano en un todo significativo para el sujeto en su mundo.

$\mathrm{Al}$ percatarse del riesgo que representa la contaminación, los individuos temen las repercusiones ambientales y consecuentemente el padecimiento del cuerpo. Según Douglas ([1966] 1999), en el mundo de los humanos el individuo aprehende objetos externos que hieren su estructura interna. En su teoría sobre pureza, contaminación y peligro, la autora sostiene la noción de necesidad de controles sociales para mantener un mínimo de estabilidad y contener el desorden sociocultural provocado por la contaminación, a la que denomina "ofensa" contra las referencias ordenadas de un contexto social. Las expresiones de los moradores de la Isla de Maré son acogidas en este estudio como construcciones culturales de modelos explicativos sobre contaminación y enfermedades asociadas (Spiro, 1996; Helman, 2003).

\section{MATERIALY MÉTODO}

La investigación fue realizada entre 2006 y 2008 con base en los siguientes instrumentos etnográficos: observación participante, registros de campo - anotaciones, fotografías, charlas-, entrevistas narrativas (Jovchelovitch y Bauer, 2007) y visitas más frecuentes a dos poblados - Bananeiras y Santana - por haber sido los más afectados por la contaminación industrial. El modo de análisis y comprensión reunió diversas nociones sobre lo simbólico en un estilo etnográfico geertziano (Geertz, 1989) con contenidos que esbozaron el objeto de estudio al interior de la organización social (Jacobson, 1984). A propósito de los enunciados simbólicos, se considera indispensable hacer una lectura de los poblados como una especie de "topología social", al observar la estructura espacial de modo inseparable de la semiología social que describe el mundo como un sistema de signos, como los habitus (Bourdieu, 1996) de las prácticas alimentarias, de la forma de trabajar en la pesca y de cómo conviven los individuos con la contaminación.

La propuesta de investigación original fue aprobada por un Comité de Ética en Investigación, de la Universidad Federal de Bahía, en 2006. Con la colaboración de los habitantes, el trabajo de campo 
fue rico en charlas y entrevistas. Las más intensas y detalladas se produjeron con 20 moradores: dos mujeres y un hombre - entre los 25 y 28 años-, nueve mujeres y cinco hombres - entre 34 y 60 añosy tres ancianos: dos mujeres y un hombre - entre $88 \mathrm{y}$ 95 años-. Se analizaron las narrativas de modo artesanal (Benjamin, 1993) y minucioso, para comprender cada enunciado con base en la experiencia del interlocutor con la contaminación ambiental. Mientras se llevaba a cabo la investigación, se realizó un trabajo educativo sobre la salud y el medio ambiente con el apoyo de estudiantes universitarios. También se practicaron exámenes bioquímicos de heces con tratamiento medicamentoso por medio de los servicios municipales de salud en actividades denominadas Ferias de la Salud (Brasil, 2007).

$\mathrm{Al}$ analizar los fragmentos de las historias de vida (Queirós, 1988) destacaron dos categorías temporales: 1) un tiempo pasado, antes de la contaminación química en el aire, correspondiente a 30 años atrás o más, y 2) el presente amenazador de la contaminación. La comprensión de los significados de la contaminación por quienes conviven con el problema proviene de sus palabras como enunciados portadores de sentido (Minayo, 2008; Eco, 2004). Los textos narrados se consideraron como inscripciones que aseguran una textura de representaciones sobre la contaminación ambiental, como un fenómeno contaminador que afecta completamente la vida del individuo. El análisis interpretativo de las narrativas procuró garantizar, en primera instancia, la gramática textual sobre la contaminación en la isla, y mantener una conexión con otros datos técnicos sobre el tema.

$\mathrm{El}$ análisis de los discursos tomó en cuenta los códigos de la cultura. Sin embargo, este estudio no trata de confrontar la información de la percepción popular con la de los requisitos técnicos de la contaminación. Su objetivo es agregar a la síntesis semántica sobre la contaminación diversas lecturas de quienes viven el problema y elucidarlo en tanto

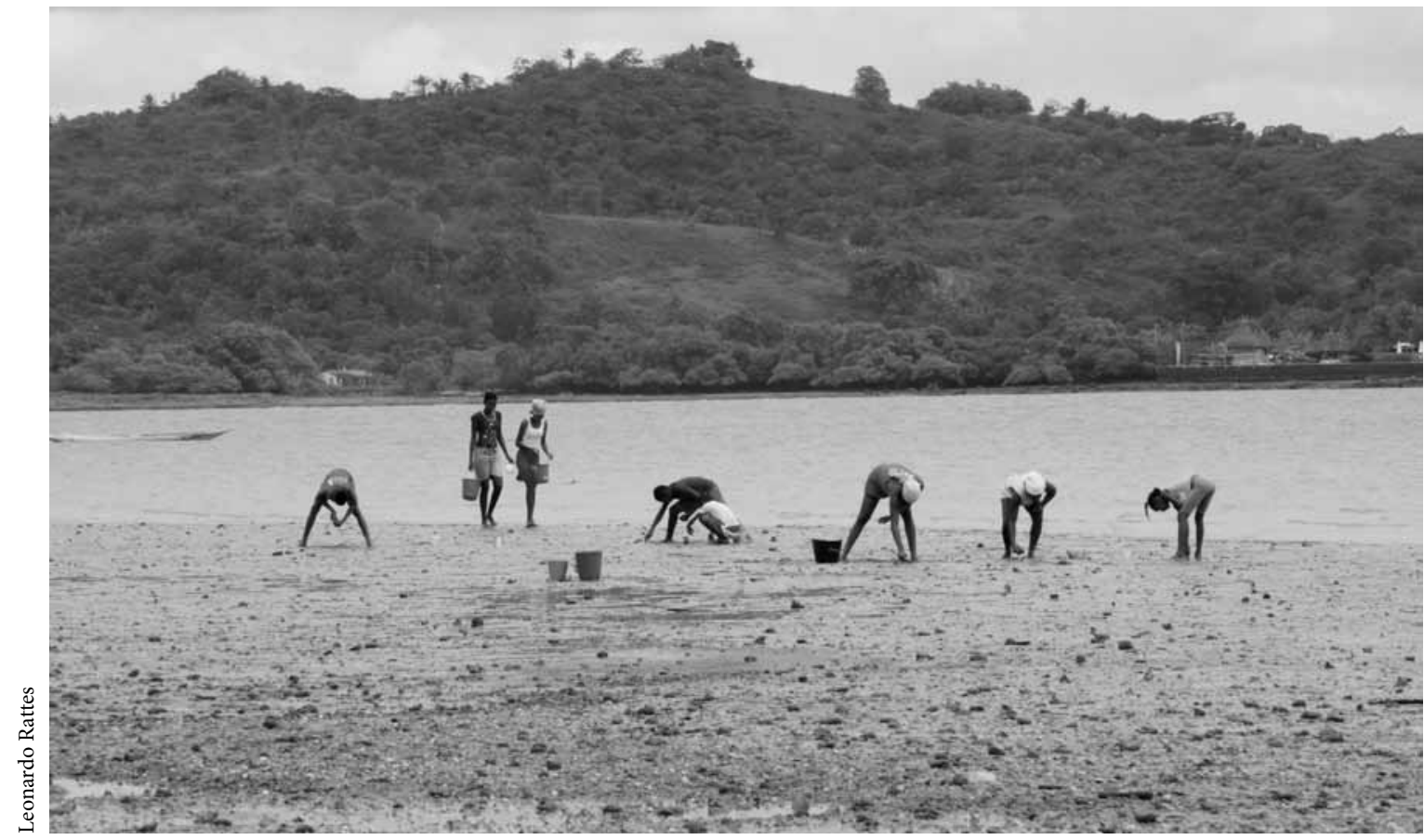

Las mujeres ejercen un papel importante en la generación de ingresos para las familias por medio de la marisquería. La tradición de selección pasa de generación en generación, 2011. 
una cuestión que afecta directamente la calidad de vida de los moradores de la isla. Al entrar en el mundo de los significados socioculturales y tratar de compartirlos, se respetaron las especificidades de los moradores, su lenguaje y sus valores, para llegar a una comprensión más amplia del problema ambiental a través de la trayectoria libre de sus discursos, sus gestos, sentimientos y silencios (Minayo, 1993). En este contexto, hombres y mujeres revelan cómo conciben y sobreviven a la contaminación ambiental, particularmente la industrial, siendo ésta la referencia más frecuente en las palabras de los moradores. El presente trabajo está constituido de la siguiente manera: 1) análisis del contexto sociocultural; 2) visión jerarquizada de la contaminación industrial y contaminación orgánica de acuerdo con la población; 3) categorías de interpretación sobre contaminación ambiental, y 4) la contaminación en la perspectiva de los moradores.

\section{EL CONTEXTO SOCIOECONÓMICO Y CULTURAL DE ISLA DE MARÉ}

En la historiografía brasileña la Isla de Maré — con $13.87 \mathrm{~km}^{2}$ de superficie y aproximadamente 6500 habitantes (Brasil-FIBGE, 2002) - es uno de los sitios más antiguos del estado de Bahía. Inicialmente poblado por indígenas, empieza a abrigar esclavos africanos en el siglo xvi (Risério, 2004). Todavía habitan ahí miembros de segunda y tercera generación de afrobrasileños. De acuerdo con testimonios de los propios habitantes, este territorio quilombola y desde 2007 distrito del municipio de Salvador, hace 20 años era un lugar seguro para proveer alimento. Esta realidad de autosuficiencia alimentaria ha sido modificada por la contaminación química permanente que afecta los espacios de producción -el manglar y el mar-, la vegetación y a las personas. Conforme la historia contada por sus habitantes, en la década de 1950 se instaló una refinería de petróleo cerca de la Isla de Maré. En los años sesenta se estableció en la misma región el Centro Industrial de
Aratú (CIA), como producto de la política de planificación de desarrollo industrial proyectada en aquella época para el nordeste de Brasil. En esa área se instalaron grandes industrias siderúrgicas, petroquímicas, químicas, metalúrgicas, plásticas y otras. Diez años después, se creó el Puerto de Aratú - a 5 kilómetros de la Isla de Maré- especializado fundamentalmente en el transporte de productos químicos provenientes del Complejo Petroquímico de Camaçari. Por tanto, la Isla de Maré está localizada cerca de un área de concentración industrial situada en la Bahía de Todos los Santos.

De acuerdo con la información obtenida de los propios moradores, la isla cuenta con instalación de agua desde 1990 y con energía eléctrica desde 1998 en sus 11 poblados: Praia Grande, Santana, Botelho, Caquende, Neves, Itamoabo, Bananeiras, Maracanã Martelo, Ponta Grossa y Porto de Cavalos. Las comunidades poseen un sistema de transporte marítimo precario, caracterizado por pequeñas embarcaciones que son un riesgo, no hay ancladeros y las personas bajan de los barcos en el mar, con niños pequeños, ancianos y enfermos en brazos. En las escuelas se imparten sólo los tres primeros años de enseñanza primaria, razón por la cual más de 800 niños atraviesan el mar para ir a una escuela donde puedan cursar los últimos niveles de educación básica. No hay servicios permanentes de salud, ni siquiera el Programa Salud de la Familia está organizado en la localidad.

La población de Isla de Maré tiene una cultura tradicional. De ahí que ante su proximidad con la contaminación química y con las enfermedades asociadas los habitantes explicaran de una manera peculiar su percepción de los olores, de la coloración del humo expelido por las industrias cercanas, del viento y de la noche de luna menguante cuando los olores de los contaminantes químicos son más fuertes. Los problemas de salud más comunes que afectan principalmente a los niños son diarreas, desnutrición y anemia -o debilidad-, parasitosis intestinal, resfriados, dermatitis, dolores de cabeza y asma (Brasil et al., 2007). Los adultos se quejan de 


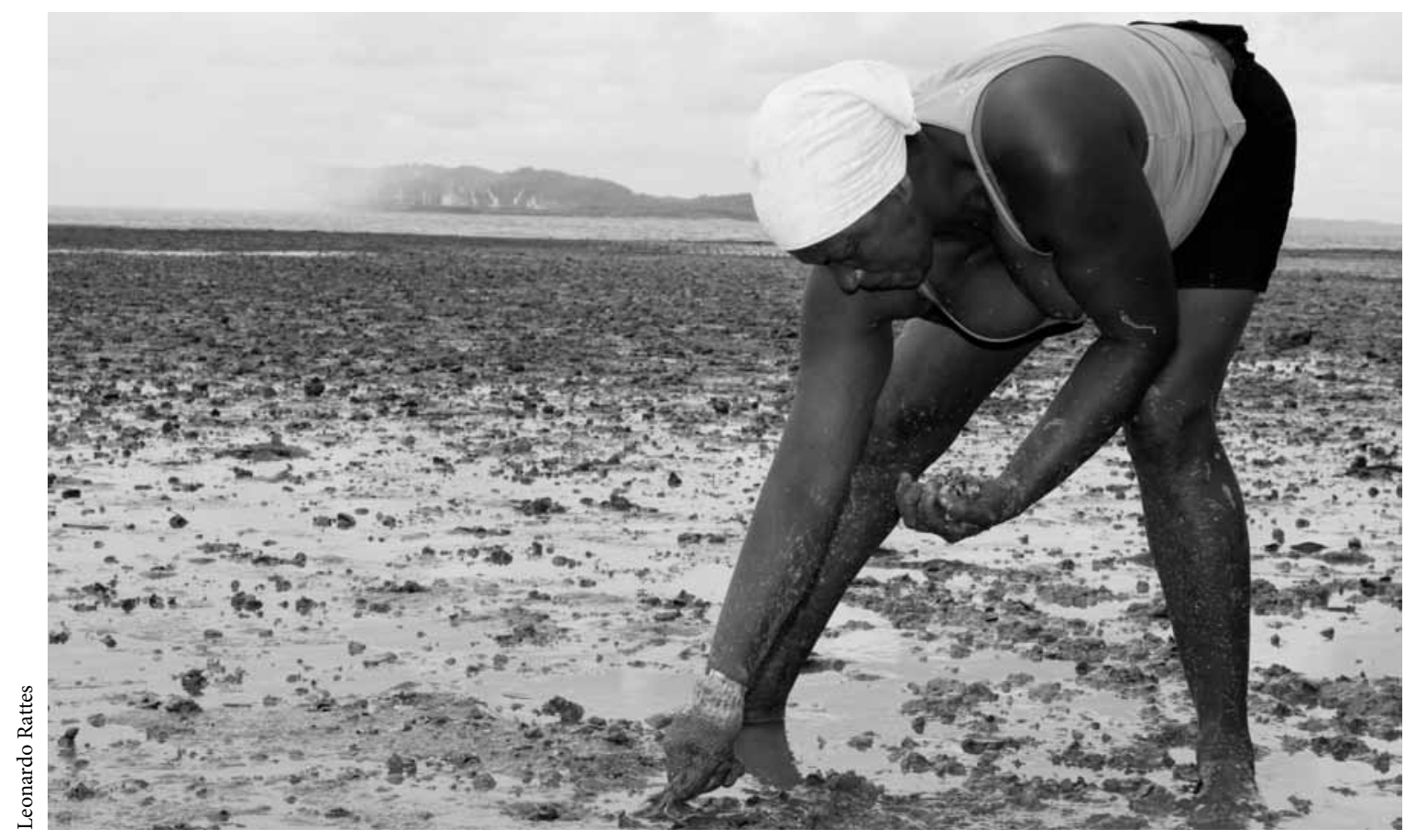

La intoxicación por metales pesados provoca disfunción renal, anemia severa y alteraciones neurológicas, entre otros problemas de salud, 2011.

diabetes, dermatitis, hipertensión, depresión, sentimiento de soledad y miedo. En general, las enfermedades son tratadas al estilo tradicional por lo difícil que es el acceso a los servicios oficiales de salud.

En sus propios términos, los moradores de la isla crearon un sistema binario de estructura de causalidad para referirse al ambiente y a los síntomas de las enfermedades: manglar y dermatitis, viento y gripe, tiempo de pesca y ceguera, mar y presión alta, luna menguante y quebranto. Con base en ese modelo prescriben tratamientos con antiguos recetarios fundamentados en una lectura mediada por fenómenos naturales y sobrenaturales conforme sus acepciones. Viento, marea y luna son los procesos naturales que, junto a las fuerzas divinas o sobrenaturales, pueden impedir o extender la contaminación en la isla.

Otro elemento necesario para la comprensión de la vida en Isla de Maré es la situación socioeconómica marcada por la tradición del trabajo de extracción manual de mariscos y de la pesca con instrumentos rudimentarios — red y caçuá-1 ${ }^{1}$ (Pena Soares de Freitas y Cardim, 2008). Esas poblaciones piensan y actúan en relación con el medio ambiente como parte del ecosistema: "Somos la misma cosa, como las piedras, el mar, el manglar, somos todo mezclado" (DN, 50 años). Según esa concepción, sociedad y naturaleza están en interacción permanente (Santos, 1996). Como se verá a continuación, en las narraciones de los moradores de Isla de Maré no hay una escisión clara entre los seres humanos y el ambiente. Esto significa que poseen una matriz interpretativa relativa al ambiente y sus problemas, como es concebida actualmente por quienes elaboran las teorías de desarrollo sostenible, en las que los seres humanos son parte constituyente de un organismo vivo y pulsante que es la tierra, la biósfera.

En dicha interacción, los aspectos subjetivos del lenguaje referentes al manglar y al mar se manifiestan como sentimientos que se comunican entre lo

\footnotetext{
${ }^{1}$ Trampa hecha de paja.
} 
humano y otros elementos de la naturaleza. En la lectura cosmológica relacionan lo sobrenatural religioso y lo ontológico: "Aquí todo tiene misterio" (AR, 38 años), "Adonde yo voy el manglar va dentro de mí, es Nanã. ${ }^{2}$ Ella nos ayuda a los de aquî" (MB, 59 años), "Sólo la gente que vive aquí hace mucho tiempo lo entiende" (Sabrina, 95 años). Muchas expresiones inscriben una visión de lo cotidiano en la que todo el ambiente importa y significa sin cesar. Uno de los conflictos de las comunidades es la disminución de mariscos y peces provocada por la contaminación química y por la pesca predatoria tradicional. A causa de esto los trabajadores vieron su ingreso mensual reducirse, pues la mayoría de la población gana en promedio menos de la mitad de un salario mínimo por mes. Anteriormente, como lo recuerdan, "muchos aquí ganaban tres salarios mínimos sólo con camarón y ostras" (DN, 50 años).

Como estrategia de supervivencia, los moradores suelen vivir en familia extensa para compartir el trabajo, los rendimientos y los gastos diarios. Hay una división del trabajo clara entre los sexos y la edad. Las mujeres, además de hacerse cargo de las labores domésticas, participan en la maricultura y los hombres en la pesca. Los niños, desde los cuatro o cinco años, ayudan a sus madres en la recolección de mariscos. A partir de los 11 o 12 años de edad, cuando los músculos de los brazos son más visibles, los niños son iniciados en la pesca, mientras que las niñas siguen en la maricultura y los quehaceres domésticos. Los ancianos arreglan las redes y participan de algunas actividades relacionadas con el marisco.

Se observan dos situaciones en relación con el cambio de hábitos alimentarios resultado de los efectos de la contaminación química: 1) la reducción de productos de pesca para el consumo - algunos platos, como el "escaldado" de mariscos, han sido prácticamente sustituidos por pescado frito acompañado de harina de mandioca preparada con el aceite de la fritura, el mismo platillo se consume una o dos veces al día-; 2) aumento del consumo

\footnotetext{
${ }^{2}$ Santa u Orixá del Candomblé
}

de productos industrializados, como aceite, galletas rellenas, caldo de pollo, extracto de tomate, carne enlatada, yogurt, botanas, jugos de fruta en polvo y pan, así como pollo congelado. Es habitual, inclusive para los niños, tomar café sin leche, con pan y margarina, en la mañana y en la noche. Esos alimentos industrializados son consumidos cada vez más por la facilidad con que los adquieren con sólo anotarlos en libretas de fiado en el comercio local. Todas las recetas de cocina se asemejan en la preparación, que se realiza en los patios comunes, bajo los árboles de mango y guayaba, donde las mujeres hacen sus quehaceres y cuidan de los niños.

Maré, además de ser un lugar, es un término que se aplica al tiempo. Es parte de la cosmología que asocia la luna y el movimiento de las mareas - grande y pequeña - cada diez o 15 días. Todo depende de la maré: el viento, la producción de pescados y mariscos, y también el humor de las personas. La marea indica una mayor o menor producción de mariscos y peces - como en las noches claras de luna llena- y un área mayor de actividad en el manglar y la parte arenosa de la playa. El ritual de extracción de mariscos en esta época es de intenso trabajo, oportuno para llevar a casa alimento suficiente para el periodo de producción reducida durante la maré pequeña. Con la llegada de la energía eléctrica surge la posibilidad de conservar los alimentos en refrigeradores, todavía escasos en la isla pero de uso colectivo entre los compañeros de pesca.

El proceso conjugado entre luna y marea se constituye como explicación, a la vez natural y sobrenatural, de las diversas maneras de percibir el cuerpo. Durante el periodo de espera de la marea grande la existencia humana manifiesta sensaciones: en las mujeres aumentan los dolores menstruales, a las mujeres que amamantan se les puede secar la leche, el abatimiento vence al niño pequeño, las marisqueras se quejan de dolores musculares y articulares más intensos en manos y brazos a causa del esfuerzo repetitivo. Mientras esperan, los hombres arreglan las redes, pescan a distancias mayores o se recogen. Las mujeres se ocupan más de la casa. La expresión maresia —olor del mar- 
está relacionada al ensimismamiento de hombres y mujeres cuando los invade una melancolía que entra en comunicación con las entidades espirituales de la marea: "Se quedan así, sintiéndola [la divinidad] junto de nosotros" (Sabrina, 93 años).

\section{VISIÓN JERÁRQUICA DE LA CONTAMINACIÓN INDUSTRIAL Y LA CONTAMINACIÓN ORGÁNICA}

El concepto de contaminación que tienen los habitantes del lugar está directamente relacionado con las dificultades que surgen en la organización social: "mucha gente se quiere ir de aquí, los jóvenes quieren salir. Aquí sólo se van a quedar los viejos que no aguantan el trancazo de la pesca. Mi hijo ya se fue" (FB, 58 años). La contaminación del medio ambiente y la contaminación dentro del cuerpo a menudo se asemejan, aun cuando algunos entienden que no todo lo que está contaminado externamente entra en el cuerpo. En este sentido, algunos plantean que la contaminación es extensiva a las personas, al manglar y al mar, lo que deriva en la reducción del camarón, la ostra y en el exterminio del cangrejo. En esta especie de trastorno ambiental se instituye como signo de peligro una figuración en el cielo: un trazo largo de humo proveniente de las chimeneas de las fábricas del Centro Industrial de Aratú que huele a ácido o a tinta y cuyo color puede ser gris, rosa, blanco o rojo. La gente dice que la contaminación química provoca ansiedad y miedo de enfermarse, principalmente en los poblados donde los contaminantes son más visibles en la atmósfera. En otras comunidades no se ve el humo, pero los habitantes perciben los fuertes olores que acarrea el viento.

Sobre la percepción temporal de los moradores, se analizan categorías relativas al pasado y al presente. Los recuerdos del lugar en el pasado representan calma y belleza, abundancia de peces y mariscos: "Nadie necesitaba salir de aquí" (Joana, 90 años), evocaciones que refieren a una "vida inocente, cuando todo mundo se entendía. Después empezó a llegar la usura, la contaminación que viene del cielo, y todo aquí cambió, todo se contamina" (José, 88 años). Esa nostalgia del lugar revela una idealización del pasado, un deseo de revivirlo y un presente amenazador que trae malestar. $\mathrm{Al}$ recordar, trascienden la realidad y se alejan de los problemas, expresan una necesidad de mantener el sentimiento de pertenencia al lugar, sin que nada externo pueda macularlo. La garantía de la restauración del sentido de la vida común en Maré se mantiene con los recuerdos de las imágenes que se refieren a la limpieza y la abundancia, pues en el pasado reciente - hace unos 15 años - se capturaban diez kilos de camarón por semana y ahora se consiguen menos de dos: “Ahora, el manglar está enfermo y Nanã está triste. Ninguna marisquera está contenta. Tienen miedo de que se acabe el manglar. Mire las hojas amarillas" (As, 56 años). Para los más jóvenes, que nacieron con la presencia de la contaminación química, hay una distancia temporal permanente entre el pasado puro y el presente impuro. Para ellos el pasado es un lugar imaginario, fuera de la realidad.

Además de esas categorías temporales y estructurantes de la vida cotidiana, las narrativas conectan su visión de la contaminación con lo que se siente en el cuerpo, con el sueño, con la comida, con las relaciones interpersonales y el trabajo. Transmiten sentidos e impresiones surgidos de su experiencia con la contaminación química, que los atormenta y los instiga. En general, consideran el ambiente "enfermo", porque “todo está contaminado" (DN, 50 años). Enfermedad y contaminación son semejantes en su cosmovisión: "la contaminación entra por la piel de la persona, por la nariz" (Fs, 27 años), "se queda atrapada en la sangre, en la barriga" ( $\mathrm{MN}, 38$ años), "hay niños que vomitan, no pueden dormir con el olor, uno siente cuando el olor entra en uno, se siente algo maligno por dentro" (MB, 53 años), "quien más lo siente son los niños, las plantas, los peces, los mariscos. Toda la naturaleza está sufriendo" (DN, 50 años).

El modelo explicativo de la contaminación ambiental presenta estructuras binarias y triangulares. Cuando se expresan interpretan los objetos de lo cotidiano 


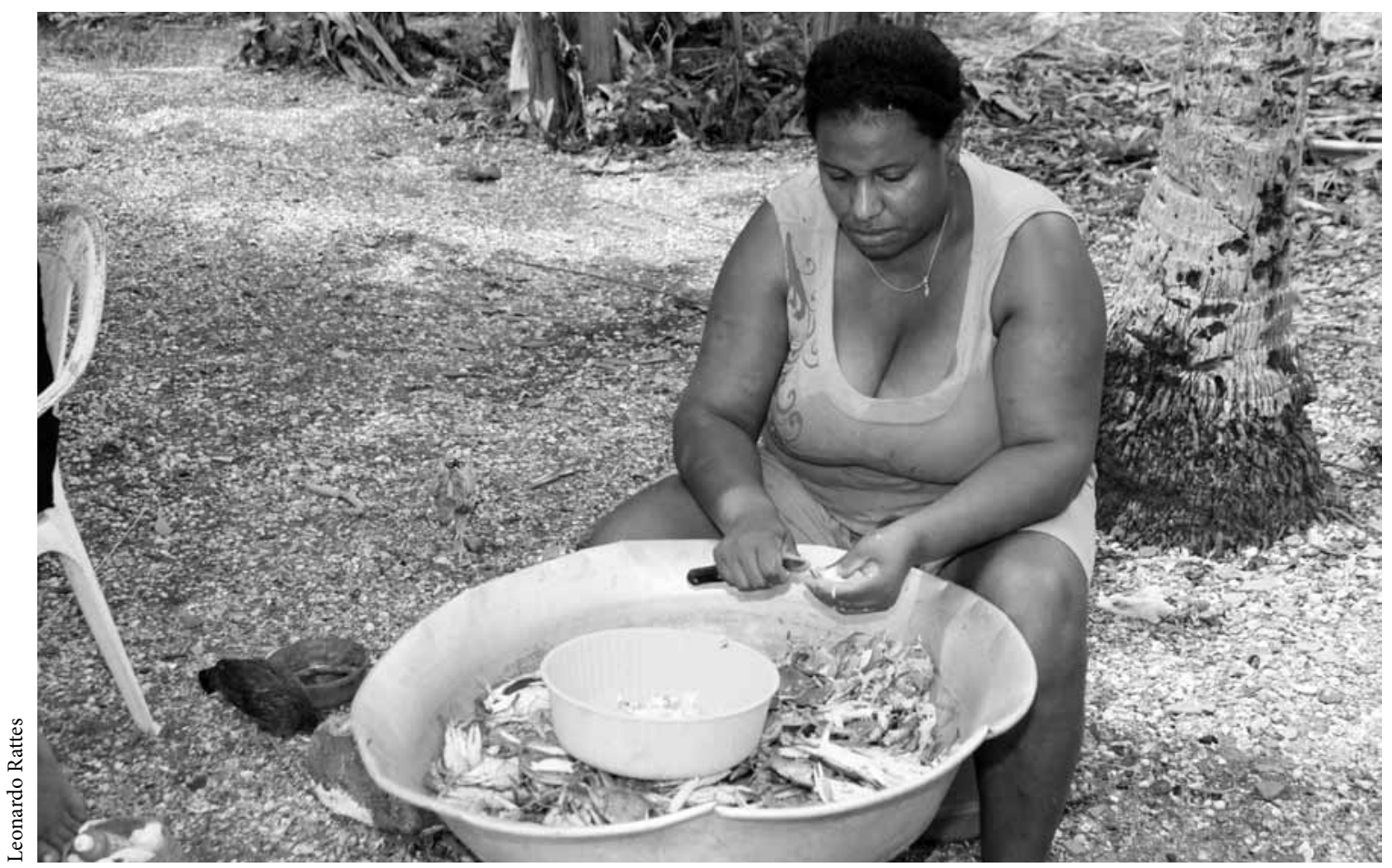

La marisquera Roquilda José Bonfim relata que algunos moluscos como el sururú ya no se encuentran más, 2011.

que tienen una conexión con ese problema: manglar/alcantarilla/basura, cielo/contaminación, noche/asma, manglar sucio/enfermedad, noche/peligro, contaminación/naturaleza de la persona, luna menguante/olor a pintura en el aire/desmame, mar desconfiado/contaminación, tristeza de Nanã/reducción de marisco. Creen, con mayor o menor vehemencia, que los fenómenos sobrenaturales y cosmológicos tienen una influencia sobre el grado, mayor o menor, de la contaminación del medio ambiente.

\section{CATEGORÍAS INTERPRETATIVAS DE LA CONTAMINACIÓN AMBIENTAL}

En el análisis de las narrativas se destacaron dos categorías generales sobre contaminación. La primera es de orden cosmológico: la noción de contaminación química y orgánica del ambiente — falta de saneamiento básico-, inclusive del ambiente sagrado, significa suciedad y ofensa. La segunda es relacional: la noción de contaminación interfiere en la naturaleza de las personas, que se perciben inmunes o no y cambian su comportamiento por el contagio de vientos y olores. Sobre la noción de contaminación del ambiente, los enunciados demuestran el conocimiento de la presencia de contaminantes químicos en la región y hacen referencia a la falta de saneamiento básico como elemento contaminador. Sin embargo, predomina la idea de que el desagüe no perjudica el manglar porque "el mar limpia todo lo malo" (AL, 40 años), imagen que resalta una explicación natural como reacción a la soledad que los moradores sienten dada la ausencia de políticas públicas. Al definir el "mar como limpiador" restauran el concepto de higiene, y esa noción de "limpieza por la mano de la naturaleza" reorganiza el contexto social. El manglar acoge el desagüe, la basura y los restos humanos que son llevados por la marea: 
El manglar no se molesta por eso. La marea logra limpiar toda la isla, le lleva tiempo pero lo logra. La marea es el manglar y el mar, lleva y trae lo que no sirve. Hasta los malos pensamientos se van [...]. Uno viene a ver la marea creciente y la bajamar. Uno viene a pedirle todo a la marea (As, 56 años).

Para los habitantes de la Isla de Maré ver el movimiento del mar es como presenciar la renovación del mundo. De la misma manera, la luna nueva viene a renovar el cosmos, la persona, el destino y la limpieza del aire. En su cosmovisión, el mar y la luna promueven un ritual divino que actúa como una forma particular de comunicación entre el ser humano y los fenómenos naturales, y entre los objetos de la realidad concreta y la dimensión subjetiva del mundo. Cuerpo y ambiente no se dividen, conforman un cuerpo "ambientado" originario de historia y tradiciones. En la isla hay otro tipo de contaminación: falta saneamiento básico o alcantarillado, no hay agua tratada en las escuelas ni filtros en las casas (Brasil et al., 2007). Los moradores usan fosas sépticas y las aguas negras corren en las calles, al aire libre, como ríos estrechos de aguas inmundas. Pequeñas tablas sirven como puentes entre un desagüe y otro, pues nadie quiere pisar esas aguas fétidas. La población sabe de la necesidad de saneamiento básico para preservar la salud, entre otros motivos porque la escuela informa sobre los riesgos de los parásitos intestinales y de las diarreas. Sin embargo, sin recursos personales ni comunitarios, y sin asistencia pública, no están en condiciones de modificar esta realidad.

Las acciones educativas emprendidas por profesores y estudiantes universitarios del área de salud en las comunidades lograron reducir la basura del manglar, pero persiste la creencia de que el manglar es un reorganizador de los restos humanos, o sea del desagüe y de la basura. Para ellos, más importante que la contaminación biológica es la contaminación química, que altera completamente la producción de alimentos. Varios moradores declararon que se puede convivir con las parasitosis y hacer tratamiento, pero no aguantan vivir con "contaminación de las químicas, porque después de ese sarro en el manglar y en la playa, los mariscos se quedaron pequeños, diferentes. Hasta el sabor cambió" (CN, 40 años). El sabor de la comida, las sensaciones y los sentimientos están relacionados con el tiempo de la marea y son afectados por la contaminación química que aparece como una nueva entidad, producida por los "hombres ricos y blancos" (DN, 50 años). Respecto de la contaminación del ambiente sagrado, una anciana comenta:

\begin{abstract}
El manglar está triste, está sucio. No se puede arrojar basura ni el desagüe en el manglar, pero ya se volvió costumbre. Desde niña aprendí que la basura se quema y se entierra. A la dueña del manglar no le gusta eso. La dueña es Nanã, la vieja que cuida al pueblo de la isla. Tiene el pelo como el mío, vive en el lodo con las mujeres de los mariscos, cuidando todo lo del lodo..., los animalitos y la gente (Sabrina, 93 años).
\end{abstract}

Los dos tipos de contaminación, industrial y orgánica, afectan los lugares sagrados de las entidades espirituales, como el mar de Iemanjá, el manglar y el viento de Nanã o la Vieja, y repercuten en el cuerpo humano. Lo mundano y lo divino son indisociables. En el dominio de lo sagrado, las entidades espirituales del manglar y del mar tienen la función de proteger los asuntos humanos. Las marisqueras se sienten protegidas en el lodo durante la captura de los mariscos, entran en silencio y al trabajar asemejan con su contoneo las ramas retorcidas de la vegetación (Castro, 1967). El cuerpo vestido de lodo mimetiza a la mujer en la figura de los animales del manglar y de Nanã: "El lodo es limpio, es la casa de la Vieja” (MN, 38 años).

Tres santas del catolicismo son veneradas en la isla: Santa Ana -Nanã en el Candomblé-, Nuestra Señora de Candeias -Oxum o Nanamburucu-, Das Neves -Oxum y para otros Iemanjá) - (Ramos, [1934] 2001). De acuerdo con la información transmitida por los habitantes del lugar, no hay tradición de Candomblé en la isla. Los pocos terreiros ${ }^{3}$

\footnotetext{
${ }^{3}$ Sitios de celebración de rituales.
} 
que existen son pequeños y fueron establecidos recientemente por grupos nagó que salieron de Itapagipe y Paripe, suburbios de Salvador. Los años de adoctrinamiento católico inhibieron la permanencia de otros tipos de sincretismo religioso indoafricanos y africanistas. No obstante, algunos Orixás siguen presentes en la memoria colectiva. Al darle relieve a la cuestión de género, cabe reafirmar el campo simbólico referente a las divinidades femeninas y la participación central de la mujer en el trabajo del manglar, además de otras actividades tradicionales, como el cuidado del ámbito doméstico.

\section{SOBRE LA NOCIÓN DE CONTAMINACIÓN: UNA SEMIÓTICA DE LA NATURALEZA ENFERMA}

Para los habitantes de Isla de Maré existen dos tipos de personas: las que tienen el "cuerpo cerrado" y la emoción resistente a la contaminación química, y las que tienen el cuerpo abierto, las emociones frágiles y son vulnerables a dicha contaminación. Siendo así, hay personas que se contaminan por sentirse frágiles y otras que todavía no. Aquellas con más resistencia no siempre sienten los efectos de la contaminación en sí, aun cuando los noten en otras personas, en la vegetación, en el aire y en el mar. Entre las creencias sobre el cuerpo contaminado destaca el tabú del cuerpo femenino, ya que la menstruación está relacionada con la noción de impureza (Sardenberg, 1994). Cuando las mujeres están menstruando no pueden entrar al manglar "para no ensuciar la casa de Nanã". Las explicaciones sobre la contaminación son parte de la creencia en un mundo sobrenatural y en los mitos que se conservan para mantener la "densidad ontológica original", en palabras de Mircea Eiade (1998: 126) al referirse al mundo abierto. Esta expresión metafórica significa la vulnerabilidad biopsíquica, los miedos y la ansiedad del sujeto frente

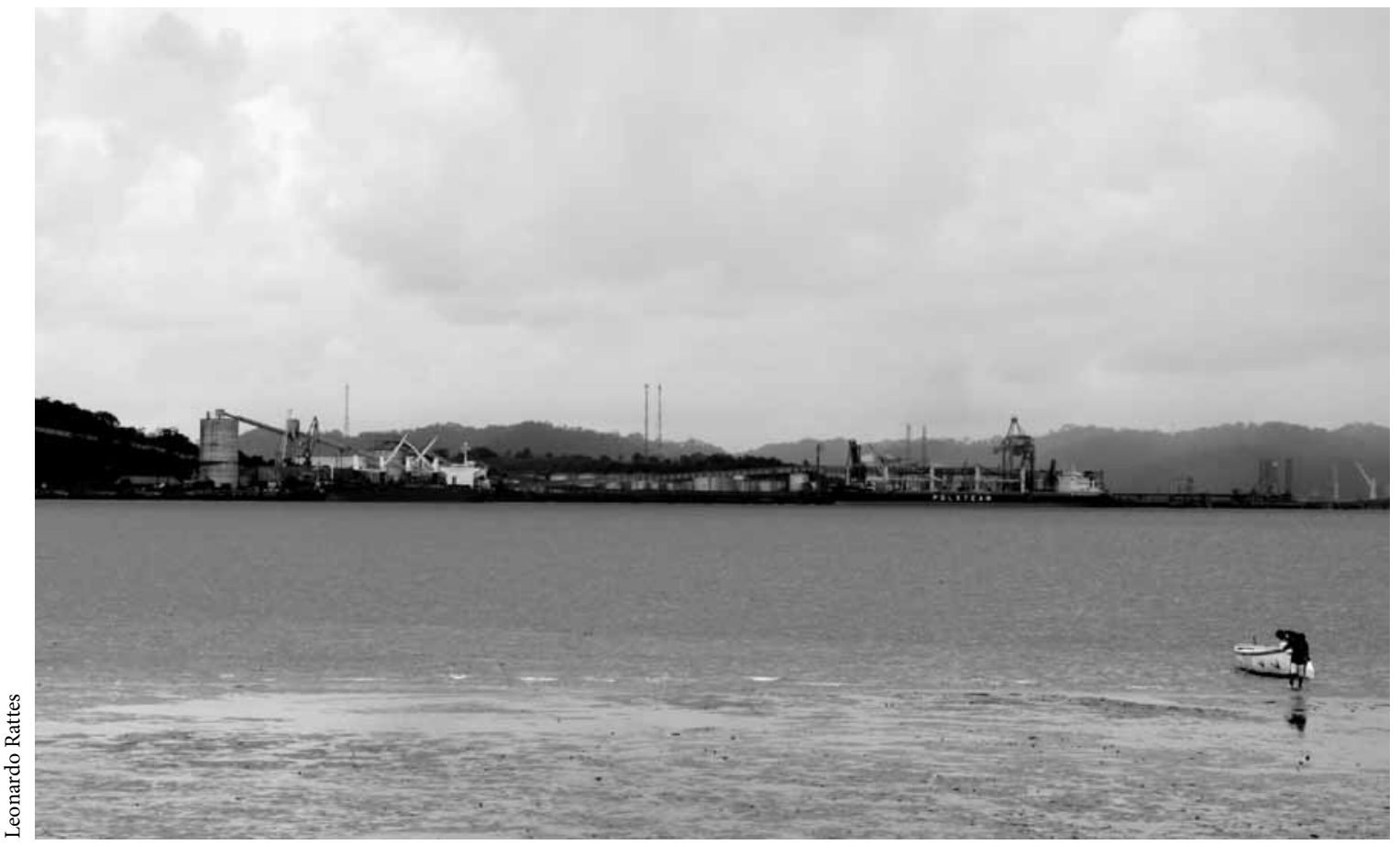

De enero a octubre de 2010 pasaron por el Puero de Aratú 4.7 millones de cargas con productos altamente contaminantes como amonia, buteno, naftalina, sosa cáustica y benceno, 2011. 
a lo desconocido y a lo que se imagina que no puede cambiar. En Isla de Maré, abierto y misterioso es el mundo herido por las químicas que vienen del aire, se mezclan con la lluvia en el mar y en el manglar, y modifican la realidad de sus habitantes. También el cuerpo se queda abierto cuando el sujeto le teme a algo. Al temer a la contaminación, el individuo puede sentirse objeto de síntomas y padecimientos.

La contaminación también es percibida como un accidente provocado por los propietarios de las industrias, quienes, según los entrevistados, estarían despojados de la creencia en Dios y por tanto son capaces de tales acciones. Algunos refieren que el universo espiritual de Isla de Maré fue alterado por este motivo. Afirman que el mar, como un ente, reaccionó a esta contaminación conforme a la metáfora siguiente: "el mar cambió y se quedó desconfiado de nosotros" (As, 56 años). Antes de la contaminación química la espiritualidad del mar -Madre del agua, Iemanjá o la Señora de las Mareas- se relacionaba más intensamente con los pescadores, lo de la emoción. En la actualidad, el "espíritu del mar" se ha alejado del lugar manchado por la contaminación química. Para otros, sin embargo, el mar es tan poderoso que sigue higienizando el medio ambiente con la fuerza espiritual: "El agua del mar limpia todo, y todo eso [la contaminación] va a pasar con el tiempo del mar" (FB, 58 años). Por eso, al imaginar el mar, el tiempo y la contaminación, los isleños evocan el espíritu de la Madre del Agua, para pedirle protección. De esa forma tienden a explicar el riesgo de la contaminación química y de las dificultades que acarrea la escasez de peces y mariscos por la voluntad divina. Ese planteamiento contribuye a justificar la permanencia de la comunidad en su lugar ancestral y a mantener la expectativa de que el error de las industrias será corregido algún día.

Desde el punto de vista personal, hay quienes se perciben inmunes a la contaminación química que afecta el manglar y el mar y por eso no están contaminados. Consideran que la contaminación viene del aire y pasa por fuera del cuerpo humano. Perjudica a

los peces y a los mariscos, ensucia el ambiente y "los animales no pueden respirar" (JN, 52 años). Suponen que es la naturaleza de la persona la que propicia el surgimiento de enfermedades. La susceptibilidad al riesgo de enfermarse es explicada de varias maneras. No se trata de evitar la contaminación por la apariencia del cuerpo, sino por la forma de ser del individuo. Su condición óntica se revela desde la infancia, cuando "se va convirtiendo en persona... cuando ya entiende, se sienta solito, mira todo. Cuando nace ya trae esa índole, pero uno no se la descubre luego" (Joana, 90 años), "La persona puede ser mala o buena y estar contaminada, llena de químicas por dentro" (As, 56 años).

Otra connotación es la relativa a los niños en relación con la desnutrición, ya que son considerados frágiles o menguados, pequeños, débiles, nacidos sin luna o en luna menguante, se tardan para andar y tienen problemas al mamar. Para las madres, esos niños son los que más sufren con la contaminación del aire, pues padecen de asma y lloran mucho. El temor a ese tipo de agresión ambiental es diferente del que sienten respecto de la contaminación orgánica o doméstica que forma parte de sus condiciones de vida, las cuales rayan en la miseria social. Por eso, el término "contaminación" es reservado para clasificar los contaminantes químicos industriales.

Para los isleños, "contaminado" es el efecto de la contaminación en el ser humano y en la vegetación. En el cuerpo, la agresión química provoca "debilidad, anemia, pérdida de peso, tristeza por nada" (MR, 27 años). También afecta la organización social: la estructura del conocimiento acerca de las causas de cualquier padecimiento de los miembros de la comunidad se apoya en otros modelos explicativos, diferentes a los de la medicina oficial, y están relacionados con un complejo campo de valores, creencias y hábitos vividos en común y con referencias en el pasado (Menéndez, 1997).

Citan síntomas de malestar y de diversas enfermedades, entre las que mencionan más frecuentemente las respiratorias. El quebranto de las fuerzas del cuerpo es asimismo un padecimiento provocado por la 
contaminación, una especie de desentendimiento del cuerpo con su naturaleza, su ambiente y las cosas sagradas. La contaminación significa la presencia de ese ente maligno y externo, al que llaman químicas en el mundo de los isleños, que causa trastornos sociales, emocionales y físicos. Al sentirse contaminados advierten en su cuerpo el "olor de las químicas", lo cual es ilustrado con una percepción de que la leche materna tiene olor a pintura. Desde el punto de vista toxicológico, se sabe que la leche materna puede presentar concentraciones de metabolitos resultantes de contaminantes liposolubles, como en el caso de los hidrocarbonatos policíclicos aromáticos (HPA), lo que podría justificar esa percepción de las mujeres (Lauwerys, 1992). Hay divergencias entre los propios isleños respecto de la leche materna contaminada, pues resulta difícil que la mujer que amamanta se imagine impura.

En los testimonios se distinguen ambivalencias semánticas: por un lado hay un conformismo con el destino: "el mundo cambia" y "todo se contamina"; por otro, una buena parte de los habitantes está consciente de que las autoridades oficiales son responsables del medio ambiente, de la falta de control sobre los contaminantes arrojados por las industrias, de que no hacen nada para evitar la contaminación química y de que tampoco le dan solución a la contaminación orgánica. Los lugareños no se consideran responsables de las acciones que pudieran resolver los problemas mencionados, ya que por ser "pobres y pequeños" no tienen valor social. Por esas aflicciones "se les va el sueño de pura tristeza" (MN, 50 años). Muchos entrevistados declararon que las personas han cambiado su comportamiento con los demás después de la contaminación química: "Se quedaron contaminadas, desconfiadas, calladas, unas se pusieron más tristes. Hay madres que no entienden a sus hijas" (AL, 40 años), "Después de la mancha en el cielo, hasta pleitos surgieron. Debe de ser el miedo a esos peligros" (José, 88 años). Descifran la raya en el cielo como algo maligno en el aire que interfiere en la manera de pensar el mundo, el lugar y en sus semejantes.
En relación con el contagio por el viento y los olores, conviene recordar que la concepción ambientalista de enfermedad -explicada con base en la teoría de los miasmas, predominante desde el siglo XVI hasta mediados del XIX - justificaba la transmisión de las enfermedades a través del aire y los olores (Gouvéia, 1999). Esa noción de causalidad fue superada por la teoría microbiana desde fines del siglo XIX. Los isleños clasifican la contaminación ambiental de naturaleza química a partir de la percepción sensorial y excluyen la contaminación orgánica porque es parte de la vida cotidiana. Los vientos y los olores pueden alcanzar el "cuerpo abierto". En este sentido, el padecimiento del sujeto es resultado de su predisposición respecto del viento "cargado" de contaminantes. Pero todo depende de la dirección del viento, que actúa por "voluntad de Dios". El viento puede traer o llevar el olor hacia otro lugar y descontaminar la isla.

En general, se interpreta el aire impuro que llega con los vientos a partir de una determinada escala de valores, entre colores del humo y vientos que vienen del mar y afectan el cuerpo que se contamina: "Entra por la nariz, por la boca, y depende de la persona, unos lo encarnan y otros se cuidan, no dejan el cuerpo abierto al viento y se cierran" (As, 56 años). “¿Por qué unos sienten las cosas y otros no?”, pregunta Áurea durante una charla con las tejedoras de encaje de Santana. Para ella, "a quien bebe aguardiente, anda turbado, sucio y andrajoso, le llega la contaminación y se le contamina el cuerpo". Los isleños usan referencias visuales sobre la contaminación. Observan el matiz del aire: 1) un tono oscuro o grisáceo es señal de mayor contaminación, sobre todo la que puede dañar gravemente el cuerpo y provocar fuertes dolores de cabeza; 2) el de color blanco y el rosa provocan asma; 3) el de color rojo con olor a gas "le quita el sueño a cualquier persona" (MB, 59 años); 4) por la noche se expiden chorros de humo que difieren de lo que se ve durante el día y riegan aun más "el polvo" (DN, 50 años) o la "mancha" (NA, 60 años), los cuales son peligrosos para toda forma de vida del lugar. 


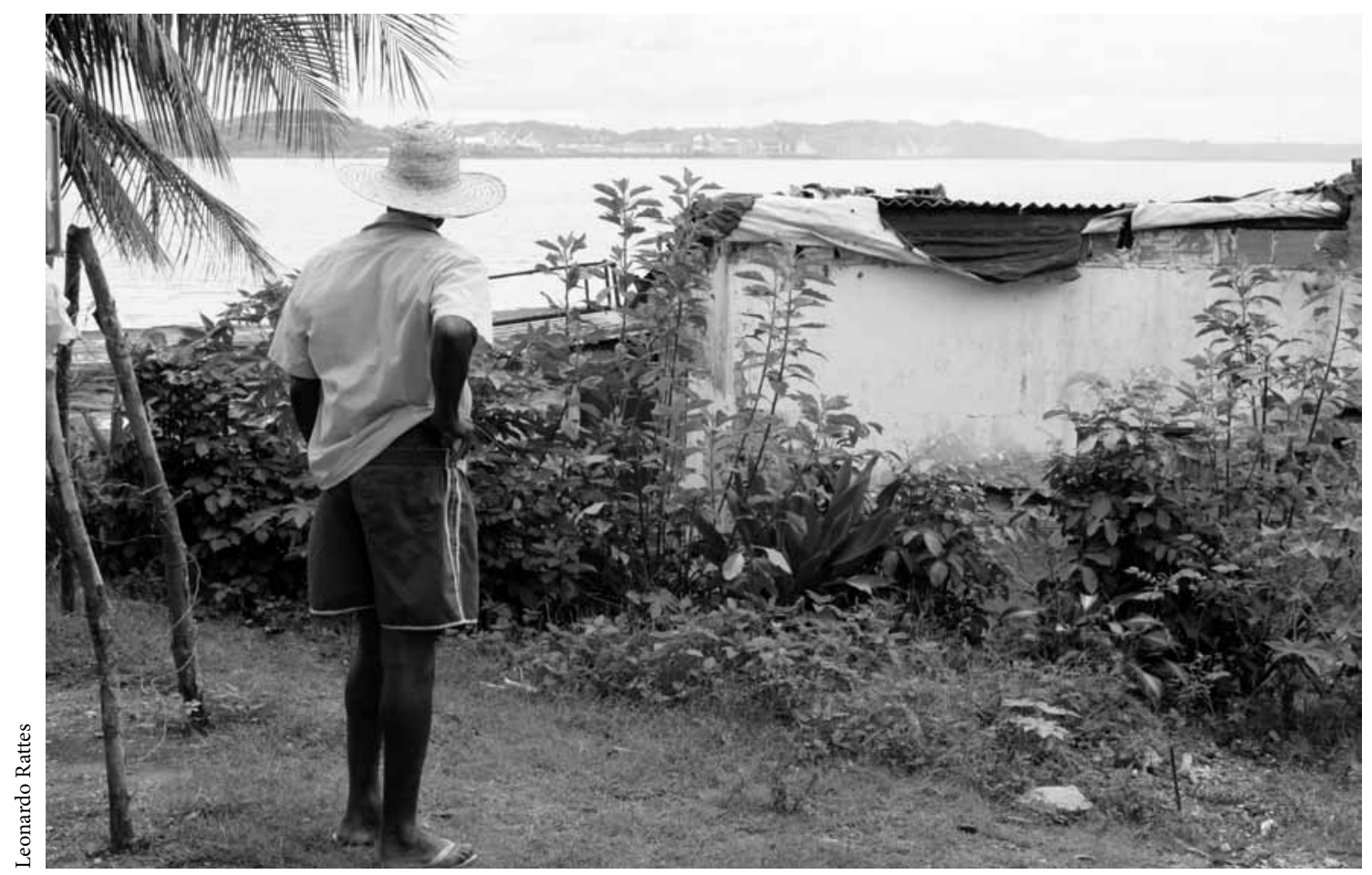

Djalma sueña con un paisaje diferente al actual: largos navíos, contaminación, peces muertos y humareda. Dice: “Tengo la esperanza de que se hará justicia", 2011.

\section{CONSIDERACIONES FINALES}

Como analistas e intérpretes de su propia condición humana, las mujeres y hombres que fueron entrevistados en la Isla de Maré entienden que los cambios ocurridos en el proceso de colecta de mariscos y de pesca están relacionados con la contaminación química. El aire está contaminado y el viento "riega". Para ellos, la contaminación es un tipo de enfermedad mundana que primero afecta el aire, el mar y el manglar, y después las frutas, los animales y a las personas. Es una enfermedad del ambiente, y para interpretarla construyen modelos explicativos, con causalidad, semiótica y modos de tratamiento natural y sobrenatural. La contaminación química o industrial es representada como una entidad externa y predadora que invade el lugar y sus tradiciones, mientras que la contaminación orgánica, producto de la falta de saneamiento básico, está incorporada a la situación de pobreza y a las condiciones de vida de los pobladores. La contaminación industrial constituye un peligro inminente para la naturaleza. En este sentido, las narrativas denuncian y representan la amenaza como un trazo en el aire o como una imagen de fondo en la escena cotidiana de Isla de Maré, que acarrea diversos síntomas de malestar y enfermedades. Las nociones de contaminación ambiental en este estudio establecen conexiones con los valores culturales de los isleños, hecho que no es considerado en las evaluaciones del impacto del desarrollo industrial. El presente trabajo, en este sentido, es una contribución a los estudios sobre el medio ambiente, pues su intención es tener en cuenta los significados de los sujetos hacia la comprensión de los desastres ecológicos y la búsqueda de prevención y disminución de los daños al medio ambiente.

Finalmente, hay que resaltar que aunque muchos de los moradores de la isla consideren que la 
contaminación química debe pasar con el tiempo - puesto que el ambiente cuenta con la protección de las entidades que habitan la localidad, apoyándose en la idea de la existencia de divinidades sanadoras-, dicha concepción no está fuera de la realidad de lo que ocurre a su alrededor, ya que todos se sienten amenazados, sin orientación y despreciados por las autoridades públicas, que no controlan las emisiones de contaminantes químicos y domésticos que afectan su modo de existir. Si bien toda la cosmología expresa una forma peculiar de ver el mundo, también tiene que ver con un modo de vivir la vida y repercute en las condiciones de supervivencia. En realidad, los moradores de Isla de Maré tienen miedo de perder la producción de mariscos, de enfermarse o de abandonar el lugar que les garantiza su trabajo y supervivencia.

\section{Bibliografía}

Benjamin, Walter, 1993, “O narrador: Considerações sobre a obra de Nikolai Leskov", en Magia e Técnica, Arte e Política, vol. 1, Brasiliense, São Paulo.

Bourdieu, Pierre, 1996, Razões práticas: sobre a teoria da ação, Papirus, Campinas.

Carvalho, Fernando Martins y Annibal Muniz SilvanyNeto, 1983, "Absorção e intoxicação por chumbo e cádmio em pescadores da região do rio Subaé", en Ciência e Cultura, vol. 35, núm. 3, pp. 360-366.

Castro, Josue de, 1967, Homens e Caranguejos, Brasiliense, São Paulo.

Centro de Recursos Ambientais, Secretaria Estadual de Meio Ambiente e Recursos Hidricos, 2001, Avaliação da Qualidade das Águas Costeiras Superficiais na Baía de Todos os Santos; Relatório Técnico, Salvador.

Consórcio Hydros, Engenharia e Planejamento, 2005, Complementação do diagnóstico do grau de contaminação da Baía de Todos os Santos por metais pesados e hidrocarbonetos de petróleo: Relatório Síntese, Centro de Recursos Ambientais, Secretaria Estadual de Meio Ambiente e Recursos Hidricos, Secretaria Estadual de Desenvolvimento Urbano, Banco Interamericano de Desarrollo, Salvador, Bahía.

Douglas, Mary, [1966] 1999, Pureza e Perigo: Ensaio sobre as noções de poluição, Edições 70 (Col. Perspectivas do homem, núm. 39), Lisboa.
Eco, Umberto, 2004, As formas do conteúdo, Perspectiva, São Paulo.

Eliade, Mircea, 1998, Tratado de história das religiões, Martins Fontes, São Paulo.

Faustino, Silvia, 2006, A experiência indizível: uma introdução ao Tractatus de Wittigenstein, Editora ENESP, São Paulo.

Ferreira, Acylene Maria Cabral, 2007, A linguagem originária, Quarteto Editora, Salvador.

Fundação Instituto Brasileiro de Geografia Estatística (FIBGE), 2002, Censo Demográfico, Brasilia.

, 2002, Pesquisa Nacional de Saneamento Básico, Brasilia.

Geertz, Clifford, 1989, A interpretação das culturas, Guanabara, Río de Janeiro.

Gouveia, Nelson, 1999, "Saúde e meio ambiente nas cidades: os desafios da saúde ambiental”, en Revista Saúde e Sociedade, vol. 8, núm. 1, pp. 49-61.

Helman, Cecil, 2003, Cultura, Saúde e Doença, Editora Artmed, Río de Janeiro.

Jacobson, David, 1984, Reading Ethnography, State University of New York Press, Albany.

Jovchelovitch, Sandra y Martin W. Bauer, 2007, "Entrevista narrativa”, en Martin W. Bauer y George Gaskell (coords.), Pesquisa qualitativa com texto, imagem e som: um manual prático, Vozes, Petrópolis, Río de Janeiro.

Lauwerys, Robert, 1992, Toxicologie industrielle et intoxications professionnelles, Masson, París.

Mahaffey, Kathryn R., 1990, “Environmental Lead Toxicity: Nutrition as a Component of Intervention", en Environment Health Perspectives, vol. 89, pp. 75-78.

Menéndez, Eduardo, 1997, "El punto de vista del actor. Homogeneidad, diferencia e historicidad", en Relaciones, núm. 69, El Colegio de Michoacán.

Minayo, Maria Cecília de Souza, 2008, "HermenêuticaDialética como caminho do pensamento social”, en Maria Cecília de Souza Minayo y Suely Ferreira Deslandes (coords.), Caminhos do Pensamento: epistemologia e método, FIOCRUZ, Río de Janeiro.

, 1993, O desafio do conhecimento: pesquisa qualitativa em saúde, Hucitec-Abrasco, São Paulo.

Ministério da Saúde (MS), Coordenação Geral de Programas de Alimentação e Nutrição (CGPAN), Escola de Nutrição da Universidade Federal da Bahia (ENUFBA), 2007, Relatório do Estudo e Pesquisa para Promoção de Hábitos de Vida e de Alimentação Saudáveis para Prevenção da Obesidade e das Doenças Crônicas Não Transmissíveis em Ilha de Maré, Salvador, Brasilia.

Okada, Isaura A., 1997, "Avaliação dos níveis de chumbo e cádmio em leite em decorrência de contaminação ambiental na região do Vale do Paraíba, Sudeste do Brasil", en Revista Saúde Pública, vol. 31, núm. 2, pp. 140-143. 
Pena, Paulo Gilvane Lopes, Maria do Carmo Soares de Freitas y Adryanna Cardim, 2008, “Trabalho artesanal, cadências infernais e lesões por esforços repetitivos: um estudo de caso em uma comunidade de mariscadeiras em Ilha de Maré, Bahia”, en Revista de Ciência e Saúde Coletiva, 17 de septiembre, en línea: <www.abrasco.org.br/cienciaesaúdecoletiva/artigos>.

Queirós, M. I. P., 1988, “Relatos Orais: do 'indizível' ao 'dizível”, en Olga de Morares Von Simson (coord.), Experimentos com história de vida, Vértice, Revista dos Tribunais, São Paulo, pp. 14-43.

Ramos, Arthur, [1934] 2001, O negro brasileiro, Graphia, Río de Janeiro.

Risério, Antonio, 2004, Uma história da cidade da Bahia, Versal Editores, Río de Janeiro.

Sachs, Ignacy, 1974, "Environnement et styles de développement”, en Annales, vol. 3, pp. 533-570.

Santos, Milton, 1996, A natureza do espaço: técnica e tempo, razão e emoção, Hucitec, São Paulo.
Sardenberg, Cecilia Maria Bacellar, 1994, "De Sangrias, Tabus e Poderes: A menstruação numa perspectiva sócio-antropológica”, en Revista Estudos Feministas, vol. 2, núm. 2, Río de Janeiro, pp. 314-344.

Silvany-Neto, Annibal Muniz y Fernando Martins Carvalho, 1996, "Evolução da intoxicação por chumbo em crianças de Santo Amaro, Bahia-1980, 1985 e 1992", en Boletín de la Oficina Sanitaria Panamericana, vol. 12, núm. 1, pp. 11-22.

Spiro, Melford, 1996, "Postmodernist Anthropology, Subjectivity, and Science. A Modernist Critique”, en Comparative Studies in Society and History, vol. V. pp. 759-780.

Tavares, Tania Mascarenhas y Fernando Martins Carvalho, 1992, "Avaliação de exposição de populações humanas e metais pesados no ambiente:exemplos do Recôncavo Baiano", en Revista Química Nova, vol. 15, núm. 2.

Ziegler, Ekhard E. et al., 1978, "Absorption of Lead by Infants", en Pediatric Research, vol. 12, pp. 29-34. 